\title{
Provider-Level Effects on Psychiatric Inpatient Length of Stay for Youth With Mental Health and Substance Abuse Disorders
}

\author{
Elizabeth Gifford, PhD, * and E. Michael Foster, PhD†
}

\begin{abstract}
Objective: Previous research on inpatient care for children and adolescents with emotional or behavioral problems indicates that patient-level factors predict length of stay (LOS) poorly. This analysis examines whether patient-level factors are poor predictors of LOS, because LOS is primarily determined by facilities rather patients.

Study Design: This study uses Tennessee Medicaid claims data from 1996 to 2001 . The data include information on 14,162 observations related to 8400 patients (age 12-21) from 163 hospitals. We estimate $\log$ LOS using a cross-classified model. Covariates include admission-level characteristics (age, diagnosis, qualification for Medicaid, year), patient-level characteristics (gender, race), and facility characteristics (facility type).

Principle Findings: Our results suggest that variation in LOS is attributable to facility-level factors (51\%), time-invariance patientlevel factors (5\%), factors that vary across admissions (42\%), and a correlation between patient-level and facility-level factors (5\%).

Conclusions: About half of the variation in LOS is explained by facility-level factors. Given the vulnerable nature of youth who are in need of inpatient psychiatric care, it may be particularly important to monitor provider-level processes and outcomes. Measuring facility or provider level quality is complicated because of difficulties in adjusting for case-mix severity across providers. The methodology presented here represents a general framework that can be widely used in health services research. Potential applications include broadening models of utilization to simultaneously include patient,
\end{abstract}

From the *Center for Child and Family Policy, Duke University, Durham, North Carolina; and †Professor of Maternal and Child Health, School of Public Health, University of North Carolina, Chapel Hill, North Carolina. Analysis of the data was funded by the National Institute of Drug Abuse (NIDA grant: R03 DA019029-01 A1, Principal Investigator: E. Gifford). Collection of the Tennessee Impact Study used in these analyses was funded by the Center for Substance Abuse Prevention (CSAP grant: UR7 TI11304, Principal Investigator: C.A. Heflinger), the National Institute of Drug Abuse (NIDA grant: R01 DA 12982, Principal Investigator: C.A. Heflinger), and the National Institute on Alcohol Abuse and Alcoholism (NIAAA grant: R21 AA12432, Principal Investigator: C.A. Heflinger).

Presented at the 24th Biennial Conference of the Society for Multivariate Analysis in Behavioral Sciences at the Friedrich Schiller University Jena, Germany in July 2004 and at "Investing in Health: 5th World Congress" International Health Economics Association in Barcelona Spain.

Contents of this article are the authors responsibility and do not represent the official view of the funding agency.

Reprints: Elizabeth Gifford, PhD, Research Scientist, Center for Child and Family Policy, Duke University, 214 Rubenstein Hall, Box 90545, Durham, NC 27708-0545. E-mail: beth.gifford@duke.edu.

Copyright (C) 2008 by Lippincott Williams \& Wilkins

ISSN: 0025-7079/08/4603-0240 provider, geographic and community level variations, as well as provider profiling.

(Med Care 2008;46: 240-246)

dentifying which patients are most likely to have a costly inpatient hospitalization is challenging. Most prior research on length of stay (LOS) focuses on patient characteristics that are readily accessible from administrative data sources such as age, gender, race, and diagnosis. However, this approach predicts LOS poorly. ${ }^{1-3}$

In various aspects of health services research, facility and provider characteristics have been identified as strong predictors of health services use. ${ }^{4-7}$ Factors external to the patient such as reimbursement policies and regulatory considerations influence physicians' decisions about patient care ${ }^{8-11}$ Providers within a facility are often subject to utilization or performance review that influences patient care. For instance, in a study of treatment of diabetic patients, the facility in which the patient was treated consistently explained substantially more of the variation than either the primary care physician or the physician group. ${ }^{12}$ One issue with prior research is that facility characteristics are potentially confounded with patient characteristics. That is, some facilities may keep patients longer not because they handle the same patient differently but because their clients differ from those of other facilities.

It seems likely that providers influence the care received by children with mental health problems. However, most studies of LOS for children with mental health disorders focus on patient factors such as basic demographic and diagnostic information. These same studies often ignore provider characteristics or use rough proxies about providers such as region or broad hospital type (acute, scatter bed, etc). In fact, many of the studies are based on samples of patients from within a single facility and thus between-facility variation is impossible to study (eg, Refs. 13-15).

The current study examines inpatient LOS for children and young adults with mental health and/or substance abuse diagnoses. The data come from a large sample that includes thousands of admissions involving thousands of patients in 163 facilities. Moreover, many patients are observed in multiple facilities. This feature of the data helps us to partition the variance across admissions, patients, and facilities. 


\section{PRIOR RESEARCH}

\section{Length of Psychiatric Stays for Children and Young Adults}

We reviewed studies that examined predictors of LOS for children with mental health and substance use disorders. Child characteristics such as gender and race predicted little to no variation in LOS. ${ }^{1,2,15-18}$ Individuals not familiar with mental health may find it even more surprising that clinical diagnoses often have not predicted LOS either. ${ }^{1,2,16,18,19}$

In fact, what emerged from these studies was the strong relationship between LOS and factors external to the child such as hospital type or region. For instance, a study by Christ et $\mathrm{al}^{1}$ found that facility characteristics explained $29 \%$ of the variation in LOS whereas demographic and clinical characteristics explained only $2-3 \%$ of the variation. Similarly, other studies have found for-profit hospital status or hospital type to predict LOS. ${ }^{2,18}$ Several studies identified region of the state or area as being a salient factor that is external to the child in predicting LOS. ${ }^{19,20}$

Although informative, these studies also suffer from several important limitations. First, the studies were not designed to examine facility-level variation in LOS. Facilitylevel variation warrants further attention because there is some evidence that resources and routines within a facility may influence patient outcomes such as LOS. Another limitation with these studies is that most are based on samples drawn from fewer than 10 facilities. Thus, the findings from the research may not generalize past the few facilities that were included in the sample.

The studies mentioned here also suffer from an important methodological limitation. In particular, the studies based on samples from multiple facilities did not adjust for the clustering of patients within the different facilities from which they were sampled. This clustering effectively decreases the sample size, and the standard errors must be inflated to reduce the type I error rate.

Our literature review found only 1 study that used a multilevel model to partition variation in LOS among individuals with mental health issues. LOS was examined using hospital discharge data from the Pennsylvania Health Care Cost Containment Council hospital discharge from 1996 to $2000 .^{21}$ The sample included discharges from patients of all ages for depression $(\mathrm{n}=190,014)$, schizophrenia $(\mathrm{n}=$ $75,693)$, and bipolar disorder $(\mathrm{n}=62,090)$ who were treated in 241 nonmilitary acute care hospitals in Pennsylvania. LOS was partitioned across 3 levels: admissions, physicians, and hospitals for depression, schizophrenia, and bipolar disorder separately. The hospital explained a relatively large amount of the variation in LOS: $27 \%, 34 \%$, and $16 \%$ for depression, schizophrenia, and bipolar disorder, respectively. The physician explained relatively less of the variance in LOS $(12 \%$, $8 \%$, and $10 \%$ ). Adding a large number of patient-level covariates and thereby controlling for case-mix severity explained relatively little of the variance in LOS for depression, schizophrenia, and bipolar disorder $(10 \%, 6 \%$, and $8 \%$, respectively). This study suggests that observable differences in patients explain less of the variation than hospital and provider characteristics. This study did not distinguish between admissions made by the same individual. Allowing this distinction would have allowed the researchers to partition the variance in LOS across patients and across hospitals and physicians.

This study partitions variation in LOS across facility and patient factors. This study is among the few to examine sources of variation in LOS for children and adolescents with mental health and substance abuse disorders. Understanding the source of variation is important for ensuring quality of care. As better measures of severity of illness become available, identifiable characteristics of the illness and the patient should drive prediction models of LOS. When factors external to the patient drive service utilization it may reflect medical uncertainty.

\section{METHODS}

\section{The Cross-Classified Multilevel Model}

As described below, the data for these analyses involve admissions of Medicaid enrollees to inpatient hospitals in Tennessee. These data include the same patient observed in different facilities. Furthermore, the data are not strictly nested. This type of structure is known as "cross-classified."22

Although increasing the computational complexity of the estimation procedure, the cross-classified data structure is advantageous for examining the question at hand. In a strictly hierarchical structure, individuals would be observed in only a single facility. For that reason, separating individual-level variation from facility-level variation would be difficult. However, in these analyses, the same individual can be observed in multiple facilities. Observing the same individual in multiple settings improves the ability to identify variation that is strictly due to (unmeasured) individual characteristics. model:

The following equations represent the cross-classified

$$
\begin{gathered}
Y_{\mathrm{i}(\mathrm{c}, \mathrm{f})}=a+\Pi X_{\mathrm{i}(\mathrm{c}, \mathrm{f})}+\mu_{\mathrm{f}}+\mu_{\mathrm{c}}+\varepsilon_{\mathrm{i}(\mathrm{c}, \mathrm{f})} \\
\mu_{\mathrm{f}}=\mathrm{BZ}_{\mathrm{f}}+\sigma_{\mathrm{f}} \\
u_{\mathrm{c}}=\Gamma X_{\mathrm{C}}+\mu_{\mathrm{c}} \\
Y_{\mathrm{i}(\mathrm{c}, \mathrm{f})}=a+\Pi X_{\mathrm{i}(\mathrm{c}, \mathrm{f})}+B Z_{\mathrm{f}}+\Gamma X_{\mathrm{c}}+\sigma_{\mathrm{f}}+\sigma_{\mathrm{c}}+\varepsilon_{\mathrm{i}(\mathrm{c}, \mathrm{f})} \\
Y_{\mathrm{i}(\mathrm{c}, \mathrm{f})}=a+\Pi X_{\mathrm{i}(\mathrm{c}, \mathrm{f})}+B Z_{\mathrm{f}}+\Gamma X_{\mathrm{c}}+\sigma_{\mathrm{f}}+\sigma_{\mathrm{c}}+\sigma_{\mathrm{f} \times \mathrm{c}} \\
+\varepsilon_{\mathrm{i}(\mathrm{c}, \mathrm{f})}
\end{gathered}
$$

where $\mathrm{i}$ indexes admission, $\mathrm{c}$ indexes child, and $\mathrm{f}$ indexes facility. The subscript $\mathrm{i}(\mathrm{c}, \mathrm{f})$ identifies the admission as nested jointly within facility $f$ and child $c$.

Equation (1) specifies that LOS for a given admission is a function of characteristics of the child that vary from admission to admission $\left(\Pi X_{\mathrm{i}(\mathrm{c}, \mathrm{f})}\right)$ (eg, diagnosis, age), characteristics of the facility, characteristics of the child, and an admission-specific variance $\left(\mu_{\mathrm{f}}, \mu_{\mathrm{c}}\right.$, and $\varepsilon_{\mathrm{i}(\mathrm{c}, \mathrm{f})}$, respectively). Equations (2) and (3) provide further detail about the facility- 
level and child-level terms, respectively. $\mu_{\mathrm{f}}$ is determined by a vector of observed facility-level characteristics $\left(Z_{\mathrm{f}}\right)$ (eg, type of facility) and a random error component $\left(\delta_{\mathrm{f}}\right) . \mu_{\mathrm{c}}$ is determined by a vector of observed nontime varying child characteristics $\left(X_{\mathrm{c}}\right)$ (eg, gender, race, ethnicity) and a random error component $\left(\delta_{\mathrm{c}}\right)$. Equations (1)-(3) can be combined, generating Eq. (4). In addition, the random effects of the facility and the child can be allowed to correlate $\left(\sigma_{\mathrm{f}} \times \sigma_{\mathrm{c}}\right)$ [Eq. (5)]. This correlation might occur if patient characteristics that affect LOS are related to facility characteristics that also predict LOS. The error terms $\varepsilon_{\mathrm{i}(\mathrm{c}, \mathrm{f})}, \sigma_{\mathrm{c}}$, and $\sigma_{\mathrm{f}}$ are all assumed to be normally distributed.

\section{Estimation}

First, a variance components model was used to partition the variance across facilities, individuals, and admissions. A variance components model is estimated with a constant term and the error terms, but no covariates. Two variance components models were estimated. One variance components model included a correlation between the facility and child random effect terms. The other model excluded this term. A log-likelihood ratio test was used to determine which model better fit the data.

Then the model was estimated with the complete set of covariates again with and without the correlated error term and a log-likelihood ratio test was used to determine which model fit better the data.

Empirical Bayes estimates of the facility and patient random terms were computed from the model including all of the covariates and the correlated residual term. ${ }^{23}$ The facility and the person level residuals were then plotted. All analyses were conducted in Stata 9.0. ${ }^{24}$

\section{Data}

The Tennessee Impact Study provided the data for this study. That study is part of a multisite investigation of the effect of managed care on the use of health services by children and adolescents. The impact study is funded by the US Department of Health and Human Services, Substance Abuse, and Mental Health Services Administration. Researchers at Vanderbilt University's Institute for Public Policy Study obtained and processed the Medicaid claims used in these analyses. The Institutional Review Board at Vanderbilt approved the original research protocol and the institutional review boards at Penn State and Duke have approved subsequent analyses of these data.

The data provide information on service use from July 1996 until December 2001. The sample includes all overnight hospitalizations where the youth's primary diagnosis was related to mental health or substance abuse. Of the observations that contain complete information, there were 14,162 observations related to inpatient visits from 8400 patients in 163 facilities. One thousand seven hundred patients in the sample received care in multiple facilities. Similarly, multiple patients were observed in 108 facilities in the analytic sample.

Relatively few observations had any item nonresponse. Ninety admissions were excluded from the analysis, $<1 \%$ of the total number of admissions, because of incomplete infor- mation on eligibility for the Medicaid program $(n=78)$ or facility identification number $(n=12)$.

As noted, the dependent variable is LOS. To correct for the right skewness in this variable, a natural log transformation was used. In this situation where the assumption of non-normality is not met, the beta coefficients do not have their usual interpretation. The most consistent and efficient means of interpreting the effect of an 1 unit change in a covariate on the nontransformed dependent variable $(Y)$ is to use smearing. ${ }^{25,26}$ In this technique, the expected value of LOS in days (rather than log-days) is based on the exponentiated value of the residuals as well as the covariates and slopes. (The percent change in the nontransformed LOS associated with a 1 unit change in the value of a covariate can easily be estimated by multiplying the beta coefficient by 100.) In addition, because some admissions resulted in very long inpatient stays, LOS was right censored at 100 days. This affected 271 admissions.

The $Z$ matrix includes variables that describe facility characteristics. A series of dummy variables were created, which indicated whether the facility was: (1) an inpatient mental health facility (eg, mental health hospital or a general hospital with a mental health ward); (2) a general hospital without a mental health ward; (3) an "other" type of facility; or (4) the provider information was missing.

The $X$ matrix consists of 2 variables that are constant within child: race (white, black, other or unknown) and gender. The $\Gamma$ matrix contains variables specific to the admission but that may vary within the child. These include the child's age at discharge, the child's eligibility status within the Tenncare program (SSI, Medically Needy/Spend Down, Foster Care, Temporary Aid for Needy Families, other state program, other poverty related vs. uninsured/uninsurable ${ }^{1}$ ), the year during which the admission occurred, the order of the visit and the order of the visit squared, as well as the patient's diagnosis at admission. Based on ICD-9 diagnoses, a series of dummy variable were created that included whether the youth was diagnosed with serious mental illness, depression, conduct disorder, anxiety, other mental illness, attention problems, developmental disorder, alcohol abuse, drug abuse, or a physical health problem. These dummy variables are not mutually exclusive as the patient may have comorbid conditions during any admission.

\section{RESULTS}

Table 1 contains descriptive information on the variables used in these analyses. Average age of the sample was 16.1 years. The average LOS was 11.5 days. LOS varied by facility type. Patients in general inpatient facilities had a shorter average LOS (3.5 days) than patients treated in mental health inpatient facilities (10.5 days), other health facilities (28.5 days) or patients treated in facilities where the specialty is missing (18 days). The majority of admissions in these data were to inpatient mental health facilities (88\%). Average LOS in these mental health facilities was approximately 6 days. LOS was longer at "other" inpatient facilities (about 13 days) and shorter in the general hospitals (about 3 days; $P<0.001$ ). 


\section{TABLE 1. Descriptive Statistics}

\begin{tabular}{|c|c|c|c|}
\hline & Mean Sta & ard De & iation \\
\hline Length of stay (in days) & 11.5 & 17.7 & \\
\hline \multicolumn{4}{|l|}{ Length of stay by facility type (in days) } \\
\hline Mental health inpatient facility & 10.5 & 16.0 & \\
\hline General inpatient facility & 3.5 & 2.5 & \\
\hline Other & 28.5 & 32.6 & \\
\hline \multirow[t]{2}{*}{ Specialty missing } & 18.0 & 24.4 & \\
\hline & 16.5 & 2.5 & \\
\hline Age & $\mathbf{n}$ & & $\%$ \\
\hline \multicolumn{4}{|l|}{ Gender } \\
\hline Male & 7769 & & $55 \%$ \\
\hline Female & 6393 & & $45 \%$ \\
\hline \multicolumn{4}{|l|}{ Race } \\
\hline White & 10,664 & & $75 \%$ \\
\hline Black & 3259 & & $23 \%$ \\
\hline Other or unknown & 239 & & $2 \%$ \\
\hline \multicolumn{4}{|l|}{ Diagnoses } \\
\hline Serious mental illness & 1889 & & $13 \%$ \\
\hline Depression & 8712 & & $62 \%$ \\
\hline Conduct disorder & 3522 & & $25 \%$ \\
\hline Anxiety & 809 & & $6 \%$ \\
\hline Attention related disorder & 873 & & $6 \%$ \\
\hline Developmental disorder & 138 & & $1 \%$ \\
\hline Alcohol diagnosis & 667 & & $5 \%$ \\
\hline Drug diagnosis & 1771 & & $13 \%$ \\
\hline Other mental illness & 2763 & & $20 \%$ \\
\hline Other nonmental health diagnosis & 1675 & & $12 \%$ \\
\hline \multicolumn{4}{|l|}{ Insurance eligibility category } \\
\hline Uninsured or uninsurable & 3087 & & $22 \%$ \\
\hline SSI & 4448 & & $31 \%$ \\
\hline Medically needy & 1349 & & $10 \%$ \\
\hline Fostercare & 2072 & & $15 \%$ \\
\hline AFDC & 2474 & & $17 \%$ \\
\hline Poverty & 544 & & $4 \%$ \\
\hline Other state program & 188 & & $1 \%$ \\
\hline \multicolumn{4}{|l|}{ Year participant entered services } \\
\hline 1996 & 1469 & & $10 \%$ \\
\hline 1997 & 2642 & & $19 \%$ \\
\hline 1998 & 2667 & & $19 \%$ \\
\hline 1999 & 3015 & & $21 \%$ \\
\hline 2000 & 2834 & & $20 \%$ \\
\hline 2001 & 1535 & & $11 \%$ \\
\hline \multicolumn{4}{|l|}{ Primary specialty of the facility } \\
\hline Mental health inpatient facility & 12,486 & & $88 \%$ \\
\hline General inpatient facility & 75 & & $1 \%$ \\
\hline Other & 284 & & $2 \%$ \\
\hline Specialty missing & 1317 & & $9 \%$ \\
\hline
\end{tabular}

Source: Author's Tabulations of the Tennessee Impact Study.

\section{Preliminary Analyses}

Preliminary analyses revealed a descriptive relationship between LOS and the facility in which the patient is treated. First, facilities whose average LOS was $>3$ weeks were identified as "long-stay" facilities. Of the 163 facilities in the sample, 35 were identified as "long-stay" facilities. The data were then subsetted to include only those patients who had visited both a "long-stay" facility and another facility in the sample. There were 283 patients who met this criteria. Together, these 283 patients had 496 admissions to long-stay facilities and 693 admissions to other facilities. For these 693 patients, the average LOS in the long-stay facilities was 44 days. In comparison, the average LOS for these same patients in all other facilities was only 11 days. A separate analysis examined whether it made difference whether the patient's first admission was to a long-stay or a nonlong stay facility. The results suggested that order did not play a role.

\section{Formal Multilevel Modeling}

Two variance components models were estimated to partition the variance across the facility-level, the child-level, and the admission-level (see Table 2). Model 1 included a constant as well as random term for the facility, the child and the residual error terms. Model 2 extended this model to include a correlation between the facility and the child random terms. A log-likelihood ratio test indicated that model 2 fit the data better than model $1(P<0.001)$. The results of model 2 suggest that $51 \%$ of the variance is explained by differences across facilities, $5 \%$ is explained by differences across patients, and $40 \%$ is explained by factors associated with the particular admission. In addition, $5 \%$ of the variance is explained by a correlation between patient and facilitylevel factors. An examination of the patient-level and facilitylevel residuals indicated that the 2 were correlated at -0.17 . This negative correlation indicates that facilities with longer average LOS tend to have patients that would have had shorter LOS had they been seen in other facilities.

Table 3 contains the results of the full cross-classified models. As earlier, the cross-classified model was estimated with (model 4) and without (model 3) allowing the child- and facility-level error terms to be correlated. Again, the loglikelihood ratio test indicated that the model with the correlated random terms was a better fit $(P<0.001)$. Therefore, only the coefficients from model 4 are discussed.

Older youth tended to have shorter LOS than younger youth. Individuals with a diagnosis of serious mental illness, depression, or conduct disorder tended to have longer lengths of stay than individuals without these diagnoses $(P<0.0001)$. LOS for individuals who qualified for Medicaid through SSI tended to be longer than individuals who qualified through any of the other mechanisms $(P<0.001)$. LOS for admissions made to specialty mental health facilities did not differ from admissions made to general inpatient facilities or "other" facilities after controlling for the other covariates in the model. LOS is shorter in the years after $1996(P<0.001)$.

The results from models 2 and 4 suggest that adding all of the covariates reduced the unexplained facility variance by $20 \%$, the unexplained patient variance by $19 \%$, and the unexplained total variance by $13 \%$.

In supplemental analyses, model 4 was extended to include a dummy variable that indicated whether the facility was a long-stay facility (as defined earlier). Adding this variable did not affect the magnitude of the beta coefficients. However, this proxy variable did explain $75 \%$ of the unex- 
TABLE 2. Results from the Variance Components Models of Log Length of Stay

\begin{tabular}{|c|c|c|c|c|c|c|}
\hline & \multicolumn{3}{|c|}{ Model 1: Variance Compents Model } & \multicolumn{3}{|c|}{$\begin{array}{l}\text { Model 2: Variance Components Model } \\
\text { With Correlated Random Component }\end{array}$} \\
\hline & Variance & SE & $\%$ Variance Explained & Variance & SE & $\%$ Variance Explained \\
\hline Facility & 0.81 & 0.12 & $51 \%$ & 0.83 & 0.12 & $51 \%$ \\
\hline Patient & 0.11 & 0.01 & $7 \%$ & 0.07 & 0.01 & $5 \%$ \\
\hline Facility*patient & & & & 0.07 & 0.01 & $5 \%$ \\
\hline Residual & 0.67 & 0.01 & $42 \%$ & 0.63 & 0.01 & $40 \%$ \\
\hline Total & 1.59 & & & 1.61 & & \\
\hline Log likelihood & -18442.1 & & & -18423.7 & & \\
\hline Log likelihood ratio test & 36.8 & $P<0.0001$ & & & & \\
\hline
\end{tabular}

Source: Author's Tabulations of the Tennessee Impact Study.

plained facility variation. Substantial variation remains among the facilities in a given classification of this variable.

\section{DISCUSSION}

The analyses presented here reify the status of the facility as a driving factor in determining LOS. First, the preliminary study demonstrated that the LOS for the same group of patients varied enormously (from 11 to 44 days) based upon the mean LOS for the facility. Second, even after controlling for a large number of covariates thought to influence LOS (Table 3), the facility continued to account for nearly half of the variance in LOS relative to only $4 \%$ explained by time invariant patient-level characteristic.

These results complement the work of others who find that facility-level practices such as case management and utilization review affect patient outcomes. For instance, a study by Wickizer et $\mathrm{al}^{27}$ suggested that administratively limiting psychiatric LOS may have negative consequences such as increasing hospital readmission rates. As the science of measuring quality of care improves, the goal should be to base treatment on patient characteristics and patient outcomes. However, studies such as these suggest that factors external to the patient are driving variation in LOS.

Future research should focus on better understanding the facility-level factors that predict whether a facility is a short-stay or a long-stay facility. It is possible that the observed differences in LOS are purely related to resource issues such as the availability of beds, funding mechanisms, or access to outpatient treatment. Alternatively, the differences could be related to the treatment philosophies of different medical teams. For example, some physicians may feel that a patient's long-term health will benefit from an extended stay away from his or her home context. Better understanding the level of treatment that is being prescribed and the rational for that treatment may improve our understanding of the cost-quality tradeoff. Unfortunately, this sort of information is rarely included in administrative datasets like the one used in this study.

The analyses do identify certain time-varying characteristics of patients that influence LOS. For example, individuals with serious mental illness stay on average $36 \%$ longer than individuals without a serious mental illness. Similarly, individuals with depression have stays that are approximately
$11 \%$ longer than individuals without depression. Individuals who qualified for Medicaid through the Supplemental Security Income Program and thus have a diagnosed long-term illness average $44 \%$ longer lengths of stay than individuals who qualified through the foster care program. The main point of these analyses was that even after controlling for these factors that begin to adjust for differences in the case-mix severity, the majority of the unexplained variation remained at the facility level.

These analyses are based on admissions made during 1996 through 2001. More recent admissions tended to have shorter LOS. This decrease in LOS coincides with the introduction of managed care to Tennessee. At the end of 1994, the Tenncare program began as a Medicaid demonstration. Relying on managed care principles, Tenncare expanded health insurance to both the Tennessee Medicaid population as well as individuals whom the state identified as uninsured or uninsurable. Consistent with other studies, the introduction of managed care seems related to decreases in psychiatric LOS. ${ }^{28}$ However, these analyses remain relevant to current research because controlling for the time trend did not affect the conclusion that facility-level factors are driving variation in LOS.

This study provides several methodological advantages over previous studies on LOS for youth with mental health and/or substance abuse diagnoses. For example, several prior studies of LOS limited the sample to patients treated within a single facility. ${ }^{14,15}$ These studies were able to explain roughly half of the variation in LOS using patient-level factors. However, if the bulk of the variance in LOS occurred between facilities then studies such as these are misleading. By examining many admissions to many hospitals, this study examined both within and between facility variations. The multilevel modeling approach provides improved estimates of the standard errors for the effects of the covariates. Most prior research on LOS ignored the clustering of patients within providers. Ignoring this clustering increases the type I error rate. ${ }^{29}$

Although the findings from the current study suggest that facility-level effects are large, the process by which facilities affect LOS remains a black box. Future studies should extend this multilevel framework to include facilitylevel information such as utilization management techniques, 
TABLE 3. Cross-classified Regression Results of Log Length of Stay

\begin{tabular}{|c|c|c|c|c|c|c|c|}
\hline & \multicolumn{3}{|c|}{ Model 3: Full Model } & \multicolumn{3}{|c|}{$\begin{array}{l}\text { Model 4: Full Model with } \\
\text { Correlated Random Component }\end{array}$} \\
\hline & & Beta & SE & $\boldsymbol{P}$ & Beta & SE & $P$ \\
\hline \multicolumn{2}{|l|}{ Female } & -0.01 & 0.02 & 0.39 & -0.01 & 0.02 & 0.46 \\
\hline \multicolumn{2}{|l|}{ Age } & -0.09 & 0.04 & 0.03 & -0.08 & 0.04 & 0.04 \\
\hline \multicolumn{2}{|l|}{ Age squared } & 0.00 & 0.00 & 0.46 & 0.00 & 0.00 & 0.48 \\
\hline \multicolumn{2}{|l|}{ Order of the visit } & 0.01 & 0.01 & 0.14 & 0.02 & 0.01 & 0.08 \\
\hline \multicolumn{2}{|l|}{ Order of the visit squared } & 0.00 & 0.00 & 0.25 & 0.00 & 0.00 & 0.38 \\
\hline \multicolumn{8}{|l|}{ Diagnosis* } \\
\hline \multicolumn{2}{|c|}{ Comorbid physical health condition } & 0.03 & 0.03 & 0.23 & 0.03 & 0.03 & 0.22 \\
\hline \multicolumn{2}{|l|}{ Serious mental illness } & 0.30 & 0.03 & 0.00 & 0.31 & 0.03 & 0.00 \\
\hline \multicolumn{2}{|l|}{ Depression } & 0.11 & 0.02 & 0.00 & 0.11 & 0.02 & 0.00 \\
\hline \multicolumn{2}{|l|}{ Conduct disorder } & 0.08 & 0.02 & 0.00 & 0.08 & 0.02 & 0.00 \\
\hline \multicolumn{2}{|l|}{ Anxiety } & 0.00 & 0.04 & 0.93 & 0.00 & 0.04 & 0.93 \\
\hline \multicolumn{2}{|l|}{ Other mental illness } & 0.00 & 0.02 & 0.86 & 0.00 & 0.02 & 0.89 \\
\hline \multicolumn{2}{|l|}{ Attention problems } & 0.06 & 0.03 & 0.10 & 0.06 & 0.03 & 0.10 \\
\hline \multicolumn{2}{|l|}{ Developmental disorder } & 0.06 & 0.08 & 0.43 & 0.06 & 0.08 & 0.46 \\
\hline \multicolumn{2}{|l|}{ Alcohol diagnosis } & 0.02 & 0.04 & 0.56 & 0.02 & 0.04 & 0.54 \\
\hline \multicolumn{2}{|l|}{ Drug diagnosis } & 0.01 & 0.03 & 0.83 & 0.01 & 0.03 & 0.82 \\
\hline \multicolumn{8}{|l|}{ Race $^{\dagger}$} \\
\hline \multicolumn{2}{|l|}{ Black } & -0.03 & 0.02 & 0.21 & -0.03 & 0.02 & 0.20 \\
\hline Other or unknown & & 0.02 & 0.07 & 0.73 & 0.03 & 0.07 & 0.65 \\
\hline Eligibility category & & & & & & & \\
\hline Uninsured/uninsurable & & -0.28 & 0.03 & 0.00 & -0.28 & 0.03 & 0.00 \\
\hline Medically needy & & -0.38 & 0.03 & 0.00 & -0.38 & 0.03 & 0.00 \\
\hline Foster care & & -0.44 & 0.03 & 0.00 & -0.44 & 0.03 & 0.00 \\
\hline Temporary aid to needy fam & & -0.49 & 0.03 & 0.00 & -0.49 & 0.03 & 0.00 \\
\hline Poverty & & -0.55 & 0.04 & 0.00 & -0.55 & 0.04 & 0.00 \\
\hline Other state & & -0.98 & 0.24 & 0.00 & -0.99 & 0.24 & 0.00 \\
\hline Primary specialty & & & & & & & \\
\hline General inpatient facility & & 0.28 & 0.28 & 0.31 & 0.27 & 0.28 & 0.33 \\
\hline Other specialty & & 0.01 & 0.17 & 0.97 & 0.01 & 0.17 & 0.94 \\
\hline Specialty missing & & -0.12 & 0.02 & 0.00 & -0.11 & 0.02 & 0.00 \\
\hline Entry year" & & & & & & & \\
\hline 1997 & & -0.17 & 0.03 & 0.00 & -0.17 & 0.03 & 0.00 \\
\hline 1998 & & -0.05 & 0.03 & 0.07 & -0.05 & 0.03 & 0.08 \\
\hline 1999 & & -0.13 & 0.02 & 0.00 & -0.13 & 0.02 & 0.00 \\
\hline 2000 & & -0.18 & 0.04 & 0.00 & -0.18 & 0.04 & 0.00 \\
\hline 2001 & & -0.27 & 0.07 & 0.00 & -0.27 & 0.07 & 0.00 \\
\hline Constant & & 3.45 & 0.36 & 0.00 & 3.44 & 0.36 & 0.00 \\
\hline & & & & I Resu & & & \\
\hline Variance Terms & Variance & SE & & & Variance & SE & $\%$ \\
\hline Facility & 0.65 & 0.09 & & & 0.66 & 0.09 & $47 \%$ \\
\hline Patient & 0.10 & 0.01 & & & 0.06 & 0.01 & $4 \%$ \\
\hline Correlation & & & & & 0.07 & 0.01 & $5 \%$ \\
\hline Residual & 0.64 & 0.01 & & & 0.61 & 0.01 & $43 \%$ \\
\hline & 1.39 & & & & 1.40 & & \\
\hline Loglikelihood & -18031.08 & & & & -18011.78 & & \\
\hline Loglikelihood ratio test & 38.59 & $P<0.0$ & & & & & \\
\hline $\begin{array}{l}\text { Source: Author's Tabulations o } \\
\text { *Categories are not mutually ex } \\
\text { †Omitted or baseline cagetory: } \\
{ }^{\dagger} \text { Omitted or baseline category: } \\
{ }^{\ddagger} \text { Omitted or baseline category: } \\
\text { "Omitted or baseline category: }\end{array}$ & $\begin{array}{l}\text { the Tennessee } \\
\text { clusive. } \\
\text { Vhite. } \\
\text { SI. } \\
\text { npatient Mental } \\
\text { 996. }\end{array}$ & $\begin{array}{l}\text { act Study. } \\
\text { lth Facility. }\end{array}$ & & & & & \\
\hline
\end{tabular}


facility bed size, patient-nurse ratios, for-profit status of the hospital, and other facility-level factors that affect resource utilization. Similarly, this framework could be extended to include physician-level variation. In other areas of health services research such as breast cancer, the age and specialty of the attending physician has predicted the variation in service utilization. ${ }^{4,5}$ In addition, this model should be extended to include other levels such as the community.

Finally, LOS is an interesting variable to researchers, insurers, and administrators because it so heavily drives the cost of care. However, better understanding the link between psychiatric LOS and the patient's emotional and functioning outcomes would improve our understanding of how to improve the effectiveness and efficiency of health care.

\section{ACKNOWLEDGMENTS}

The authors thank Craig Anne Heflinger, Robert Saunders, and Anna Marie Brannon for their comments on early drafts.

\section{REFERENCES}

1. Christ AE, Tsemberis S, Andrews H. Childhood disorder DRG: consideration for a predictive model. $J$ Am Acad Adolesc Psychiatry. 1989;28: $47-52$.

2. Eisen SV, Giffin M, Sederer LI, et al. The impact of preadmission approval and continued stay review on hospital stay and outcome among children and adolscents. J Ment Health Adm. 1995;22:270-277.

3. Tucker P, Brems C. Variables affecting length of psychiatric inpatient treatment. J Ment Health Adm. 1993;20:58-65.

4. Keating NL, Weeks JC, Landrum MB, et al. Discussion of treatment options for early-stage breast cancer: effect of provider specialty on type of surgery and satisfaction. Med Care. 2001;39:681-691.

5. Richardson LC. Treatment of breast cancer in medically underserved women: a review. Breast J. 2004;10:2-5.

6. Andersen R. Revisiting the behavioral model and access to medical care. $J$ Health Soc Behav. 1995;36:1-10.

7. Grossman SJ, Hart OD. An analysis of the principal-agent problem. Econometrica. 1983;51:7-45.

8. Ross SA. The economic theory of agency: the principal's problem (in decision making under uncertainty). Am Econ Rev. 1973;63:134-139.

9. Robinson JC. Theory and practice in the design of physician payment incentives. Milbank Q 2001;79:149-177, III.

10. Dranove D, White WD. Agency and the organization of health care delivery. Inquiry. 1987;24:405-415.

11. Buchanan A. Principal/agent theory and decision making in health care. Bioethics. 1988;2:317-333.

12. Krein SL, Hofer TP, Kerr EA, et al. Whom should we profile? Exam- ining diabetes care practice variation among primary care providers, provider groups, and health care facilities. Health Serv Res. 2002;37: $1159-1180$.

13. Lyons JS, O’Mahoney MT, Larson DB. The attending psychiatrist as a predictor of length of stay. Hosp Community Psychiatry. 1991;42:10641066.

14. Gold J, Shera D, Clarkson B. Private psychiatric hospitalization of children: predictors of length of stay. J Am Acad Child Adolesc Psychiatry. 1993;32:135-143.

15. Pottick K, Barber CC, Hansell S, et al. Changing patterns of inpatient care for children and adolescents. J Consult Clin Psychol. 2001;69:573-577.

16. Leon SC, Snowden J, Bryant FB, et al. The hospital as predictor of children's and adolescents' length of stay. $J$ Am Acad Child Adolesc Psychiatry. 2006;45:322-328.

17. Pottick K, Hansell S, Gutterman E, et al. Factors associated with inpatient and outpatient treatment for children and adolescents with serious mental illness. J Am Acad Child Adolesc Psychiatry. 1995;34: 425-433.

18. Pottick KJ, Hansell S, Miller JE, et al. Factors associated with inpatient length of stay for children and adolescents with serious mental illness. Soc Work Res. 1999;23:213-225.

19. Leon SC, Uziel-Miller N, Lyons JS, et al. Psychiatric hospital service utilization of children and adolescents in state custody. $J$ Am Acad Adolesc Psychiatry. 1999;38:305-310.

20. Patrick C, Padgett DK, Burns B, et al. Use of inpatient services by a national population: do benefits make a difference? J Am Acad Child Adolesc Psychiatry. 1993;32:144-152.

21. Harman JS, Cuffel BJ, Kelleher KJ. Profiling hospitals for length of stay for treatment of psychiatric disorders. J Behav Health Serv Res. 2004; 31:66-74.

22. Rasbash J, Browne W. Modelling non-hierarchical structures. In: Leyland AH, Goldstein H, eds. Multilevel Modelling of Health Statistics. Chapter 7. London, England: Wiley; 2001:93-105.

23. Rab-Hesketh S, Skrondal A. Multilevel and Longitudinal Modeling Using Stata. College Station, TX: Stata Press; 2005.

24. StataCorp. College Station, TX: StataCorp LP; 2005.

25. Duan N. Smearing estimate: a nonparametric retransformation method. J Am Stat Assoc. 1983;78:605-610.

26. Afifi AA, Kotlerman JB, Ettner SL, et al. Methods for improving regression analysis for skewed continuous or counted responses. Annu Rev Public Health. 2007;28:95-111.

27. Wickizer TM, Lessler D, Boyd-Wickizer J. Effects of health care cost-containment programs on patterns of care and readmissions among children and adolescents. Am J Public Health. 1999;89:1353-1359.

28. Hutchinson AB, Foster EM. The effect of Medicaid managed care on mental health care for children: a review of the literature. Ment Health Serv Res. 2002;5:39-54.

29. Goldstein H, Browne W, Rasbash J. Multilevel Modelling of Medical Data. London, England: Institute of Education, University of London; 2002. 